2020-08-25

Reducing energy demand in China and the United Kingdom: The importance of energy literacy

Cotton, Debby

http://hdl.handle.net/10026.1/16201

10.1016/j.jclepro.2020.123876

Journal of Cleaner Production

Elsevier BV

All content in PEARL is protected by copyright law. Author manuscripts are made available in accordance with publisher policies. Please cite only the published version using the details provided on the item record or document. In the absence of an open licence (e.g. Creative Commons), permissions for further reuse of content should be sought from the publisher or author. 


\section{Journal Pre-proof}

Reducing energy demand in China and the United Kingdom: The importance of energy literacy

D.R.E. Cotton, J. Zhai, W. Miller, L. Dalla Valle, J. Winter

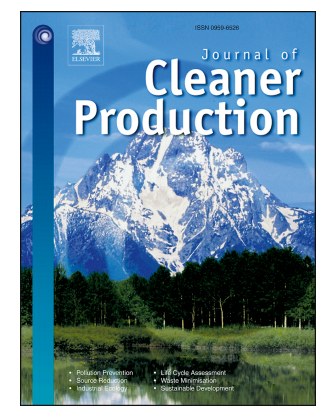

PII:

S0959-6526(20)33921-4

DOI:

https://doi.org/10.1016/j.jclepro.2020.123876

Reference:

JCLP 123876

To appear in: Journal of Cleaner Production

Received Date: 6 May 2020

Revised Date: 18 August 2020

Accepted Date: 21 August 2020

Please cite this article as: Cotton DRE, Zhai J, Miller W, Dalla Valle L, Winter J, Reducing energy demand in China and the United Kingdom: The importance of energy literacy, Journal of Cleaner Production, https://doi.org/10.1016/j.jclepro.2020.123876.

This is a PDF file of an article that has undergone enhancements after acceptance, such as the addition of a cover page and metadata, and formatting for readability, but it is not yet the definitive version of record. This version will undergo additional copyediting, typesetting and review before it is published in its final form, but we are providing this version to give early visibility of the article. Please note that, during the production process, errors may be discovered which could affect the content, and all legal disclaimers that apply to the journal pertain.

(C) 2020 Published by Elsevier Ltd. 


\section{CRediT Author Statement}

Cotton, D.R.E.: Conceptualisation; Methodology; Funding acquisition; Supervision; Formal analysis; Resources; Writing - Original Draft

Zhai, J.: Methodology; Validation; Data Curation; Formal analysis; Investigation; Writing - Review \& Editing; Project administration

Miller, W.: Methodology; Validation; Data Curation; Formal analysis; Investigation; Writing - Review \& Editing; Project administration

Dalla Valle, L.: Methodology; Validation; Data Curation; Formal analysis; Writing - Review \& Editing

Winter, J.: Conceptualisation; Methodology; Funding acquisition; Writing - Review \& Editing 


\section{Reducing energy demand in China and the United Kingdom: The importance of energy literacy}

\section{Authors:}

Cotton, D.R.E.(a), Zhai, J. (b), Miller, W. (c), Dalla Valle, L. (c) and Winter, J.(a)

Affiliations:

(a) Plymouth Marjon University, Plymouth, UK

(b) Zhejiang University, Hangzhou, China

(c) University of Plymouth, UK

Corresponding author:

Debby Cotton dcotton@marjon.ac.uk 
Reducing energy demand in China and the United Kingdom:

The importance of energy literacy

\section{Authors:}

Cotton, D.R.E.(a), Zhai, J. (b), Miller, W. (c), Dalla Valle, L. (c) and

Winter, J.(a)

\section{Affiliations:}

(a) Plymouth Marjon University, Plymouth, UK

(b) Zhejiang University, Hangzhou, China

(c) University of Plymouth, UK

Corresponding author:

Debby Cotton dcotton@marjon.ac.uk 


\title{
Reducing energy demand in China and the United Kingdom:
}

\section{The importance of energy literacy}

\begin{abstract}
:
As the impacts of climate change become increasingly visible across the globe, awareness of the need for cleaner energy and demand reduction is growing. Energy literacy offers a strong potential for explaining and predicting energy-related behaviours, yet research and policies focused on this topic remain limited. In this study, energy literacy was measured in a sample of 2806 university students in the United Kingdom and China, in addition to their wider environmental attitudes using the New Ecological Paradigm scale. Findings indicate that energy literacy was relatively high overall, but there were significant differences between the knowledge, attitudes and behavioural intentions of participants in the two countries. Whilst the UK respondents rated themselves significantly more highly on perceived knowledge of energy issues, Chinese respondents provided significantly more correct answers in a knowledge test. UK respondents demonstrated more positive attitudes towards energy conservation than those from China, and were more likely to report energy-saving behaviours. However, Chinese respondents exhibited higher levels of trust in government and businesses to take action on energy issues. This paper provides a novel insight into cultural differences which may be crucial to policy and practice, and evidences the potential benefits of utilising a combination of educational and structural change to support transition to a cleaner, lowenergy society.
\end{abstract}

Keywords: Energy literacy; higher education; knowledge; attitude; behaviour; policy

Funding: This research did not receive any specific grant from funding agencies in the public, commercial, or not-for-profit sectors.

Word count: 7736 excluding references 


\section{Reducing energy demand in China and the United Kingdom:}

\section{The importance of energy literacy}

\section{Introduction:}

The need to address "the current trajectory of potentially catastrophic climate change" has become increasingly urgent in recent years, as emphasised by a recent paper signed by 15,000 scientists from over 184 countries (Ripple et al., 2017, p. 1026). Worldwide, various COP $^{1}$ meetings have set targets to reduce levels of greenhouse gas emissions and pollutants from fossil fuel burning. At the same time, attention has turned to individuals' and consumers' demand for energy: households account for around $30 \%$ of overall energy use, yet factors involved in energy behaviours are complex (Sütterlin et al., 2011). As Stephenson et al. (2010) note, the International Energy Agency (IEA) concluded in 2008 that a "huge stepchange" was needed in attitudes towards energy efficiency and in consumer behaviours. Nonetheless the latest IEA report notes that "energy-related emissions hit another historic high in 2018" (IEA 2019, np). IEA projections indicate that rising incomes and larger populations could push up global energy demand even further in future years, and the 2019 report indicates a slowing of energy efficiency improvements together with a continued upward trajectory in energy demands worldwide (IEA, 2019).

International efforts are currently focused on ensuring that global temperature rise does not exceed $2^{\circ} \mathrm{C}$ above pre-industrial levels and 184 countries, including China and the UK (as part of the EU), have ratified the Paris Agreement, committed to reducing $\mathrm{CO}_{2}$ emissions. China is currently the largest single $\mathrm{CO}_{2}$ emitter, with more than 10 billion tons of emissions in 2014, mostly from coal consumption though there is a significant policy push to move towards renewable sources of energy (Li and Taeihagh, 2020). As well as the expansion of renewables in China, 2019 was the first full year of operation for seven large-scale nuclear reactors in the country (IEA, 2020). However, private vehicle numbers in China continue to grow and individual behaviour change mechanisms are being combined with electrification technologies in an

\footnotetext{
${ }^{1}$ 'Conference of the Parties' involving all states that are subject to the UN Climate Change Convention.
} 
attempt to reduce energy use and air pollution issues (Wang et al., 2020). In the UK, output from coalfired power plants fell to only $2 \%$ of electricity generation in 2019 and for the first time renewables generated more electricity than all fossil fuels combined during the summer months of 2019 (IEA, 2020). At the same time, buildings have been found to account for a significant proportion of UK greenhouse gas emissions (19\% in 2016), with 76\% of these emissions attributable to domestic households (Hafner et al., 2019). Thus, individual behaviour is a key aspect of sustainability and cleaner production.

Despite evidence of progress, given the ambitious $\mathrm{CO}_{2}$ reduction targets which are needed, reducing energy demand in both countries is imperative. Within the sustainability and cleaner production literature, the twin foci of moving towards renewable energy sources and reducing consumption of energy through behaviour change and efficiency enhancements are key themes (Al-Obaidi and NguyenHuynh, 2018). Policy efforts are frequently focused on motivating individual pro-environmental behaviour including energy saving (e.g. DEFRA, 2008; SCR, 2006). Yet there are currently few studies which explore understandings of and attitudes towards energy-saving, and still less research that considers international patterns. Energy literacy (outlined below) offers a guiding framework for assessing an individual's knowledge about energy, attitudes towards energy conservation and renewables, and intended and actual behaviours. This research aims to compare the energy literacy of student respondents in the UK and China and consider the possible theoretical and policy implications.

\subsection{Energy literacy and energy saving}

Initiatives promoting behaviour change towards energy saving at individual and household levels form an important part of the wider suite of policies to reduce carbon dioxide emissions and meet international targets (Geller et al., 2006; Hafner et al., 2019). Some research indicates that household energy consumption can be reduced by nearly $30 \%$ without individuals making major economic or other sacrifices (Gardner and Stern, 2008). However, without a strong motivation and support for for changing behaviour, this is unlikely to happen, thus understanding energy-related behaviour has become a major 
area of study (e.g. Borne, 2009; Zhang et al., 2013; Sarkis, 2017). Extant research indicates the importance of cognition (Wang et al., 2020), values or personal norms (Shi et al., 2019) and organisational culture (Zhang et al., 2013). Research by Lorenzoni et al. (2007) indicates that, even when people are motivated to change energy behaviours, they often lack accurate useable information about positive energy-saving actions. Energy saving behaviours are too often framed as curtailment activities (turning lights off) rather than efficiency improvements or major lifestyle changes (such as dietary adaptations), and it has been found that many people engage in low-effort, low-impact actions rather than make more far reaching changes (Attari et al., 2010). Brewer et al. (2013) evaluated an approach to energy-saving in dormitories at the University of Hawaii which used game-based tools and visualisations in an attempt to encourage behavioural change. In addition to saving energy, the researchers observed some improvements in students' understanding of energy from engaging in such activities, as did Senbel et al. (2014), who found that participation was motivated by the actions and stories of their friends. However, Hafner et al. (2019) found game-based approaches less enthusiastically received by their target group of participants in the UK social housing sector. Much of this research is focused on specific groups who are the target of energy conservation activities rather than the wider student population or general public.

In addition, there has been limited research exploring energy literacy as a key underpinning variable in making effective behavioural decisions. Most previous research on energy literacy has been undertaken in US schools (e.g. DeWaters and Powers, 2011; Bodzin et al., 2013), although Lee et al. (2015) conducted similar research in Taiwan, thus providing a wider cultural context in which this concept has been tested. The need for an integrated approach to energy literacy is illustrated by research evidence indicating that both students and the public have a patchy understanding of energy issues (Barrow \& Morrissey, 1989; Attari et al., 2010), and that, although high levels of concern about energy are frequently expressed, lower levels of knowledge and skills often prevail. The energy literacy model set out by DeWaters and Powers (2011), embeds these different elements in a tripartite framework. According to these authors, energy literacy, “... encompasses broad content knowledge as well as affective and behavioural 
characteristics, [that] will empower people to make appropriate energy-related choices and embrace changes in the way we harness and consume energy." (p.1699). Energy literacy includes:

- knowledge and understanding about energy, its use and impact on environment and society (cognitive);

- appropriate attitudes and values, for example, on existence of global issues and the significance of personal decisions and actions (affective); and

- appropriate intentions/behaviours, for example to promote energy conservation, make thoughtful decisions, advocate change (conative).

The importance of each of the different elements in the tripartite model remains somewhat debated (see Bang et al., 2000, Genc and Akilli, 2016). DeWaters and Powers (2011) argue that energy saving behaviours correlate more strongly with affect than knowledge; however, Cotton et al. (2016b) indicate the importance of knowledge in addition to positive attitude in guiding appropriate energy conservation behaviours. Several researchers note that even when people are motivated to engage in energy-saving, they may lack sufficient understanding to make appropriate decisions (e.g. Gardner and Stern, 2008; Lorenzoni et al., 2007).

These debates echo the wider discussion in the literature about the origins and motivators of behavioural change. These are often dated back to work by Fishbein and Ajzen (1975) on the Theory of Reasoned Action (TRA). This posited that individual behaviour was determined by a person's behavioural motivation which was itself influenced by attitudes and subjective norms associated with the specific behaviour. A subsequent Theory of Planned Behavior (TPB) was invoked in a 1991 paper to include perceived control or agency (Ajzen, 1991). The reasoning behind the TPB is that individuals' actions are chosen based on an analysis of the possibilities and that the optimum outcome is thus achieved (Lane and Potter, 2007). It is notable that knowledge plays little role in these theories and the widespread view has been that 
knowledge about (for example) sustainability issues is insufficient in itself to prompt behaviour change (Blake, 1999; Kollmuss and Agyeman, 2002). In a recent paper on behaviour change models and energy conservation (Sarkis, 2017), knowledge is barely mentioned. However, the energy literacy model invokes knowledge as part of a wider picture, and increasingly research suggests that it does have a part to play in helping people make rational decisions about energy saving.

More recent theoretical debate has moved towards exploring social models of behaviour change, which are nuanced to the context in which a behaviour takes place, and offer a challenge to the linear, 'rational choice' behaviour change models (Stern, 2000; Jackson, 2005). The importance of context in proenvironmental behaviour is evident when considering the increase in recycling which has occurred across much of Europe. Whilst unquestionably dependent upon individual behavioural change, this has only been achieved with the help of policy intervention and major infrastructure investment to encourage and enable behavioural shifts (Barr and Gilg, 2007). Two broad theoretical approaches in this mould are Social Practice Theory (Reckwitz, 2002; Shove, 2010; Hargreaves, 2011) and Sustainable Transition Management (Rotmans et al, 2001; Verbong and Loorbach, 2012). Proponents of these theories argue that there is a need for more fundamental changes in society that go beyond the agency of individual actors. Social practice theorists view pro-environmental behaviours, not as individual choices constrained by external barriers, but as actions which are embedded within and occurring as part of social practices themselves (Hargreaves, 2011). In a similar vein, transition approaches attempt to take account of different spheres of influence including macro level (nations or federations of states), meso (networks, communities and organizations) and micro (individuals) (Rotmans et al., 2001). Rooted in systems thinking, transition theorists understand change as a long-term process involving a deep integration between society, technology, institutions and people; thus, in order to move to a low carbon economy, a combined technological and social transformation is needed. Transitions towards sustainability entail a substantial challenge to the status quo, and a radical rethink of social and technological structures. 


\subsection{Acknowledging sustainability in East and West}

Despite the differing contexts in terms of industrialization, development and economic growth, both the UK and China have experienced increasing interest in cleaner production and sustainability over recent years. In the UK, drives towards sustainability have included declaration of a climate and environment emergency by UK Members of Parliament (Chaplain, 2019), strong engagement of young people in climate change activism, and an increasing expectation on universities and colleges to show leadership on sustainability. A Climate Commission for UK Higher and Further Education was launched in November 2019, building on earlier work by sector bodies including a sustainability publication by the higher education funding council for England (HEFCE, 2008); and guidance document on education for sustainability produced by the key quality assurance body for UK universities (QAA, 2014). Policy drivers have affected universities in different ways: Across much of the sector, 'campus greening' initiatives (particularly energy-saving measures by estates teams) have progressed rapidly (Leal Filho, 2010); however, embedding sustainability within the curriculum has been slower and more mixed. While some students are exposed to opportunities to learn about sustainability issues through their curriculum, significant variations exist depending upon the course studied (see Hopkinson et al., 2008; Cotton et al., 2009). Nonetheless, there are signs that some universities are seeking to integrate sustainability into teaching, as well as through research, campus management and community relations (Sterling et al., 2013).

China offers an interesting perspective owing to its development trajectory characterised by rapid social and technological advances often accompanied by poor environmental quality (Wang and Che, 2007). China overtook the US as the world's largest carbon emitter in 2007, in part owing to its status as 'the workshop of the world', and in part due to its population size and dependence on coal-based energy sources (Zhang, 2010). However, China is committed to energy saving and investment in renewables and the Communist Party of China is addressing these issues through President Xi's environmental reform 'Ecological Civilisation' (Plenary Session of the 18th Central Committee, 2013). As far back as 1994, 
universities were identified as playing a key role in enhancing education quality and the capacity for sustainable development in China's Agenda 21 declaration. Universities in China have received encouragement for embedding sustainability in their work and responses include the establishment of the United Nations (UN) Institute of Environment for Sustainable Development at Tongji University in 2002 and the UN University Regional Centre of Excellence in ESD at Beijing Normal University in 2006. A number of Chinese Universities are signatories of the Talloires Declaration (1990), and the China Green University Network (2011) exhorts HEls to commit to sustainability by signing the Tongji Manifesto (Yuan, et al., 2013).

Great care needs to be taken when making cross-cultural international comparisons, as the interpretation of sustainability principles will vary between different social contexts. Stephenson et al. $(2015$, p.6123) define a culture as "a relatively distinctive and integrated system of knowledge, belief and behaviour that both creates and is reinforced by its material objects." The key elements of culture are norms, practices and contexts, evidenced at different temporal and spatial scales, from individual to society, short and long-term. Efforts to develop cross-cultural frameworks such as those by Rokeach (1973) and Hofstede (2001) have been critiqued by Gao et al. (2016) amongst others, for offering an over-simplistic view of cultural dimensions. Fougère and Moulettes (2007) contend that Hofstede's model constructs a world characterised by 'developed and modern' versus 'traditional and backward' in a colonial discourse. Kim (2007) further critiques the model as a binary positing Western vs non-Western values, despite clear evidence of coexistence of contrasting cultural orientations within each context, and notes that "elements of seemingly opposite worldviews may exist at the cultural and individual levels" (p.28). Others argue that there is a surprising consensus regarding the priority ordering of values across societies although individuals differ substantially in importance they attribute to each (Schwartz, 2012). Nonetheless, there are undeniably differences between the cultures in the UK and China: As Zhang et al. (2013) note, "China is a country with high collectivism and Western countries are more individualism. In this situation, the effect of personal norm (which is an individual moral factor) on individual employee 
behavior might be stronger in Western countries than its effect in China." (p. 1126). In sustainability, even the language used may have differing nuances across international contexts - and the involvement of an intercultural team on this project was crucial to enable appropriate translation. There continues to be a need for greater understanding of how sustainability is understood and manifested in varied international contexts, and this study is the first to illustrate how energy literacy is understood in China and the UK.

\section{Methodology}

\subsection{Aim and research questions}

The aim of this research was to undertake a critical investigation of students' knowledge, attitudes and reported energy-saving behaviours in selected universities in China and the UK. Key questions were:

- What are the responses of students to an energy literacy survey in the domains of knowledge, attitudes and behaviour?

- In what ways and to what extent are there differences between the responses of participants from the UK and those from China?

- What are the implications of these findings for policies regarding energy conservation and education?

These research questions aimed to explore the similarities and differences between different aspects of energy literacy across the two groups of respondents. There are clearly some limitations to such a comparison, including the difficulty of translating concepts across very different cultural and social contexts. These are discussed further below.

\subsection{Methodological context}

The current study builds on existing work by the authors exploring energy literacy amongst UK and other European students (Cotton et al., 2015; 2016 a \& b). Here we expand the sample to include students at Chinese universities to enable wider cross-cultural comparisons. We compare the knowledge, attitudes and self-reported behaviours of participants in two countries with very different approaches to 
sustainability using existing scales and validated instruments. Ethical approval was obtained through the lead university in the UK. The research involved an international team from the UK and China to ensure that translation was accurate and appropriate to the context, and that the cultural setting could be taken into account at all stages of the research.

In any multi-lingual study, a possible confounding factor is the level of common understanding across the different samples (Tsui et al., 2007). Great care was therefore taken with the translation process and piloting: The original questionnaire was translated into Chinese by three postgraduate students who were majors in English language and literature. The second author completed the back-translation with any misunderstandings discussed and resolved through this forward and back-translation process. 18 Chinese undergraduate students were then interviewed regarding all the items listed in the translated questionnaire to ensure that all items were well-understood by the interviewees. As Lee et al. $(2015$, p.11) discuss, instructional context can matter more than variances in cultural or institutional contexts. Nevertheless, cultural differences such as communication styles and levels of trust (Barkema et al., 2015), must be borne in mind in the discussion of results.

\subsection{Survey design and delivery}

The survey instrument contained 40 questions exploring energy knowledge, attitudes and behaviours, and consisted of a mix of ranking, Likert-type scale, closed and open questions. A version of the survey developed by Cotton et al. $(2015)^{2}$, was used, with some modifications to ensure accurate translation into Chinese. This survey has been used in previous research in the UK, Portugal and Belgium (Cotton et al., 2015; 2016 a \& b; Franco et al., 2018), and is currently being piloted in Brazil. The section on energy knowledge included questions probing general understandings of energy systems, for example, the definition of renewable energy, or an understanding of $35 \%$ efficiency, as well as more technical questions, such as which type of light bulb uses least energy. The survey also incorporated the widelyused New Ecological Paradigm (NEP) scale (Dunlap, 2008), and questions on perceptions of social and

\footnotetext{
${ }^{2}$ Available here: https://www.researchgate.net/profile/Debby Cotton2/publications
} 
environmental priorities (strengthening the economy, reducing inequality, climate change etc.). The NEP was used because it provides a validated scale of individuals' attitudes and concerns about environmental issues and indicates the extent to which respondents subscribe to an ecocentric (values centred on ecology) or technocentric (values centred on technology) worldview (see O'Riordan, 1981 for further discussion of these positions). The section on behaviours asked respondents about their behavioural practices, such as paying more for environmentally products, or turning heat down in rooms. For the affective and behavioural domains the same 5-point Likert scale was used, and examples of individual and social actions were included. Higher scores on these scales generally denote more positive attitudes toward energy-related issues or more effective energy-saving behaviours.

Two groups of students participated in the survey; both were from Higher Education (HE) institutions. One group were studying in the UK at 3 different institutions $(N=1248)$; the other group were studying in China at five different institutions ( $\mathrm{N}=1558)$. All were undergraduate students from mixed year groups at large, multi-disciplinary institutions (rather than specialist colleges). All the students surveyed in China were from 985/211 universities (now called "double world-class construction" universities). The Chinese government launched the "double world-class" initiative in 2015 to support universities and disciplines and promote their development as world-leading centres, and it is these universities which are most similar to international institutions in terms of resources and teaching approaches. Student participants were not known to be part of any targeted energy-saving activities; the aim was to access students who were representative of those in each $\mathrm{HE}$ system, and closer to those of the general public, rather than having any specialist knowledge or experience. The survey was conducted online using SurveyMonkey in the UK and Wenjuanxing ( $\underline{w w w . w j x . c n})$, a similar tool, in China. Invitations to complete the survey were issued by email to all undergraduate students in the universities sampled. To minimise self-selection bias, we offered entry into a Prize Draw for an iPod Touch in the UK, and a $f 50$ Amazon gift card in China. 


\subsection{Data analysis}

Descriptive statistics were calculated to summarize and compare Chinese and UK students' questionnaire responses and statistical analyses were undertaken to identify any significant differences or associations between the responses of students in the two countries. Nonparametric tests were used since most of the data are measured on a nominal or ordinal scale and are not normally distributed. For nominal variables, frequency tables and the Chi-square test of independence were computed. For ordinal variables, measures of location and spread, such as the mean and standard deviation, and the MannWhitney $U$ test were calculated. The statistical analyses were implemented using SPSS, Version 24.

\section{Results}

\subsection{Sample characteristics}

The sample consisted of 2806 respondents in total; 1558 from China and 1248 from the UK. The gender and discipline mix of respondents is shown in Figures 1 and 2. Around $56.4 \%$ of respondents from China were female, compared to $64.9 \%$ in the UK sample (see Figure 1). There were a higher proportion of students studying Science and Technology subjects, and fewer studying Medicine and Nursing programmes in China compared to the UK (see Figure 2). Where these factors may have influenced results, mention is made of them in the sections below.

\section{Figure 1: Gender}
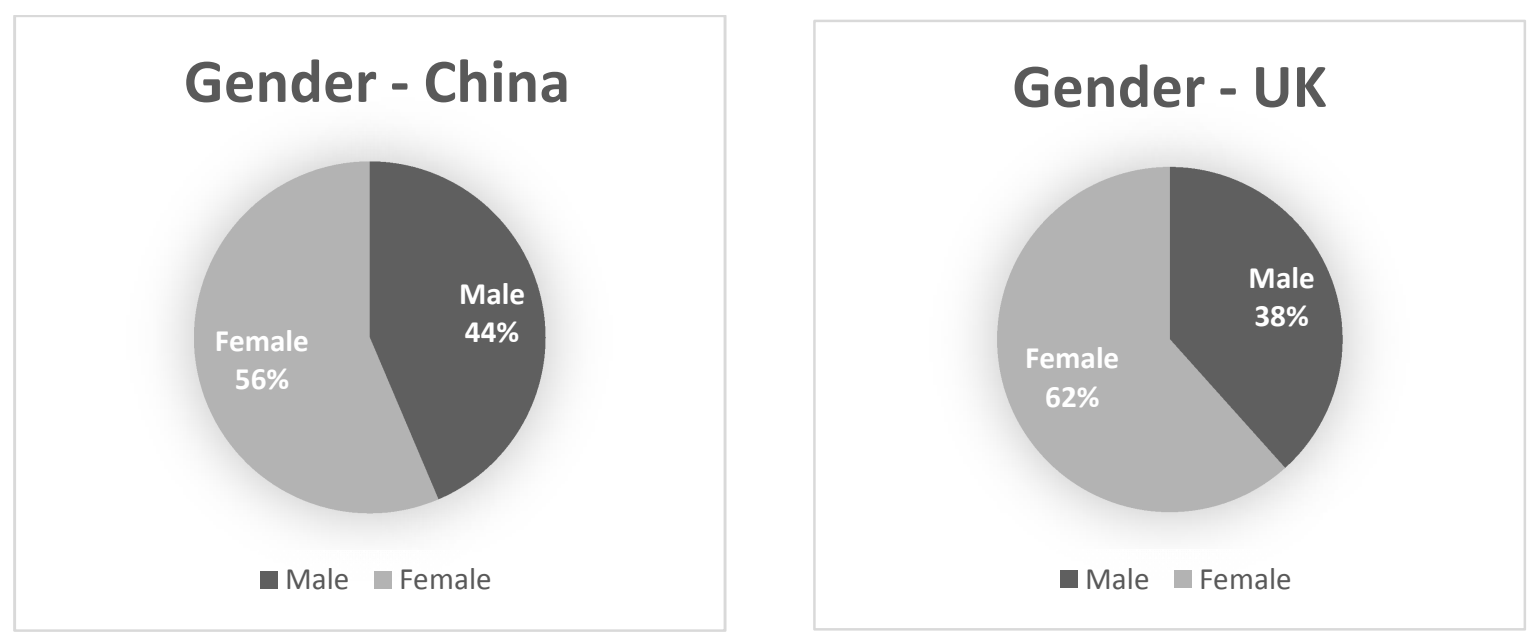

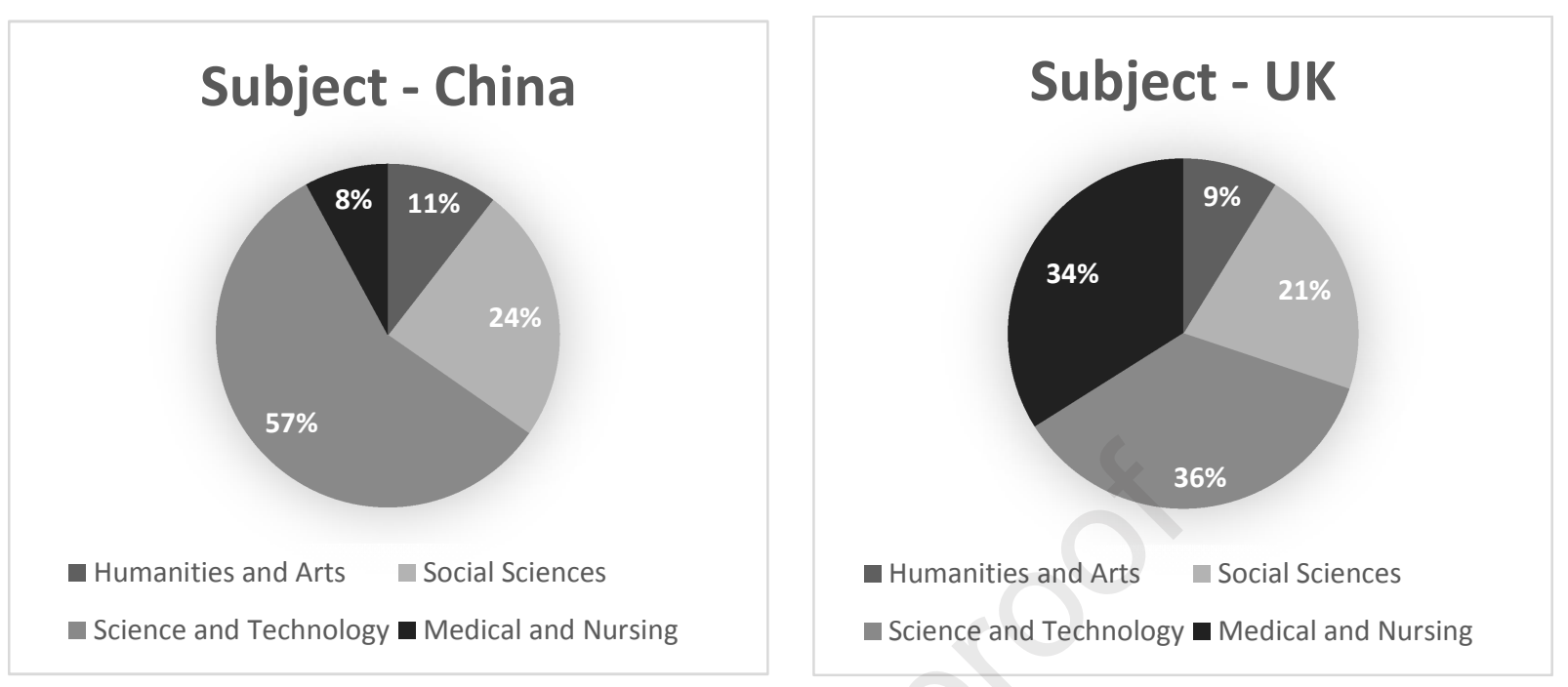

Table 1 indicates students' self-identified sources of knowledge about energy issues in each country, and their perception of the most important energy-related issue in their country. Students in the UK were most likely to identify formal education contexts (school, further and higher education) as the source of information that had contributed most to their understanding of energy issues, as has been found in other research (DeWaters and Powers, 2011). Students in China were most likely to describe the internet as contributing most to their understanding, with $40.9 \%$ of them identifying this as their most important source of information. These differences were compared using a chi-square test (Chi-square $(6)=595.91$, $p=.000$ ), which showed a significant association between the sources of knowledge and the respondents' country. There were also significant (Chi-square $(5)=189.698, p=.000$ ) differences between respondents from the UK and China in terms of their perceptions of the importance of different social and environmental issues. As illustrated in Table 1, the UK respondents were most likely to identify 'reducing inequality' as the most important issue affecting their country, whilst Chinese respondents most commonly selected 'improving educational standards' as the most important issue of concern. Surprisingly, neither group identified the energy-related issues ('climate change' and 'secure energy supply') as the most important concern in any great numbers. 
Table 1: Sample Characteristics

\begin{tabular}{|l|l|l|}
\hline & China \% (N=1558) & UK \% (N=1248) \\
\hline Source of knowledge of energy: & & \\
\hline School & 11.2 & 27.9 \\
\hline Further or higher education & 12.5 & 18.9 \\
\hline Books, newspapers or magazines & 26.8 & 15.4 \\
\hline Friends or family members (including parents) & 1.8 & 9.4 \\
\hline Internet & 40.9 & 17.6 \\
\hline Television & 5.9 & 8.3 \\
\hline Other & 0.8 & 2.4 \\
\hline Perception of the most important issue in their country: & & 16.3 \\
\hline Limiting climate change & 12.8 & 11.1 \\
\hline Reducing inequality & 22.1 & 25.6 \\
\hline Preventing wars and nuclear threats & 2.3 & 16.5 \\
\hline Strengthening the economy & 26.0 & \\
\hline Improving educational standards & & \\
\hline
\end{tabular}

\subsection{Knowledge}

The first set of questions explored the knowledge aspect of energy literacy. There were significant $(U=$ 2731579, $p=.000$ ) differences in self-reported knowledge between Chinese and UK respondents, with UK respondents rating their knowledge more highly (See Table 2). This is an interesting finding, since the UK sample consisted of a higher proportion of females - and our previous research suggests that male students tend to give higher ratings of their own knowledge (Cotton et al., 2015). However, there may well be cultural or subject differences coming into play here. 
Table 2: Perceived Knowledge

\begin{tabular}{|c|c|c|c|c|}
\hline & \multicolumn{2}{|c|}{ Country } & \multirow[b]{2}{*}{ Total } \\
\hline & & China & UK & \\
\hline How much do you & $1=$ Nothing & $3.8 \%$ & $5.3 \%$ & $4.8 \%$ \\
\hline \multirow{3}{*}{$\begin{array}{l}\text { feel you know } \\
\text { about energy? }\end{array}$} & 2=Not much (novice) & $68.2 \%$ & $56.8 \%$ & $60.1 \%$ \\
\hline & 3=Quite a bit (informed) & $26.4 \%$ & $36.8 \%$ & $33.8 \%$ \\
\hline & 4=A lot (expert) & $1.5 \%$ & $1.2 \%$ & $1.3 \%$ \\
\hline \multicolumn{2}{|l|}{ Total } & $100.0 \%$ & $100.0 \%$ & $100.0 \%$ \\
\hline
\end{tabular}

When considering the questions testing students' knowledge of energy, the Chinese students scored significantly more highly overall. Differences between the two groups were largely in relation to technical questions (in which Chinese respondents scored better) and a practical question on energy saving (in which UK students scored better). This could relate to the discipline differences between students within the sample - since the Chinese group contained more students who were studying science and technology, and students from these disciplines might be better informed about energy issues. Most students from both countries could accurately define renewable energy; only around half in either group were aware of the source of most renewable energy in their respective countries. However, Chinese students scored more highly on a question asking about energy-efficient lighting (Chi-square(1) = 191.273, $p=.000$ ), and about their understanding of what it means for a power plant to be $35 \%$ energy efficient (Chi-square $(1)=8.979, p=.003$ ), whilst the UK students scored more highly on identifying the most energy-saving daily behaviours (Chi-square $(1)=240.035, p=.000$ ).

\subsection{Attitudes}

Table 3 summarises respondents' attitudes towards a range of energy issues. A Mann-Whitney test revealed that there were significant $(U=1617424, p=.000)$ differences in the energy-related attitudes of Chinese and UK respondents for every item. Overall, the UK participants had more positive attitudes 


\section{Joumal Pre-proof}

towards most issues than Chinese participants; however, exceptions were some items which related to trust and influence, with the Chinese respondents expressing a stronger sense of agency and trust towards government and businesses. Echoing these findings were the results of the test of differences in attitudes towards ecological sustainability which was conducted using the New Ecological Paradigm Scale (NEP). This analysis indicated that the UK students had a significantly more ecological world-view (U= $1328237, p=.000$ ) than the Chinese respondents (mean scores on the scale were 2.78 for Chinese students and 3.39 for UK students). 


\section{Journal Pre-proof}

Table 3: Attitudes toward energy issues (mean score out of 5 on Likert scale, with higher score indicating more agreement). [1 = strongly disagree, 5 = strongly agree]. Highlighted box shows which group had stronger agreement.

\begin{tabular}{|c|c|c|c|}
\hline Energy-related attitudes: & $\begin{array}{l}\text { China mean } \\
\text { (SD) }\end{array}$ & $\begin{array}{l}\text { UK mean } \\
\text { (SD) }\end{array}$ & $\begin{array}{l}\text { Mann- } \\
\text { Whitney test }\end{array}$ \\
\hline I would do more to save energy if I knew how & $\begin{array}{l}2.69 \\
(1.29)\end{array}$ & $\begin{array}{l}4.09 \\
(0.78)\end{array}$ & $\begin{array}{l}U=1240125 \\
p=.000\end{array}$ \\
\hline $\begin{array}{l}\text { The way I personally use energy does not make a } \\
\text { difference to the national energy situation }\end{array}$ & $\begin{array}{l}2.72 \\
(1.14)\end{array}$ & $\begin{array}{l}2.25 \\
(0.99)\end{array}$ & $\begin{array}{l}U=2287366.5, \\
p=.000\end{array}$ \\
\hline $\begin{array}{l}\text { I can influence what the government does about energy } \\
\text { problems }\end{array}$ & $\begin{array}{l}3.04 \\
(0.96)\end{array}$ & $\begin{array}{l}2.65 \\
(1.01)\end{array}$ & $\begin{array}{l}U=2323751 \\
p=.000\end{array}$ \\
\hline $\begin{array}{l}\text { I can influence what companies do about energy } \\
\text { problems }\end{array}$ & $\begin{array}{l}3.13 \\
(0.97)\end{array}$ & $\begin{array}{l}2.54 \\
(1.03)\end{array}$ & $\begin{array}{l}\mathrm{U}=2029215 \\
\mathrm{p}=.000\end{array}$ \\
\hline $\begin{array}{l}\text { I trust the government to do something about any energy } \\
\text { problems }\end{array}$ & $\begin{array}{l}2.86 \\
(0.97)\end{array}$ & $\begin{array}{l}2.52 \\
(1.03)\end{array}$ & $\begin{array}{l}U=2441919, \\
p=.000\end{array}$ \\
\hline Scientists will find ways to solve energy problems & $\begin{array}{l}2.82 \\
(1.08)\end{array}$ & $\begin{array}{l}3.66 \\
(0.86)\end{array}$ & $\begin{array}{l}U=1663330 \\
p=.000\end{array}$ \\
\hline $\begin{array}{l}\text { More wind farms should be developed to generate } \\
\text { electricity, even if they are located in scenic environments }\end{array}$ & $\begin{array}{l}2.99 \\
(1.01)\end{array}$ & $\begin{array}{l}3.59 \\
(1.13)\end{array}$ & $\begin{array}{l}U=2026657.5 \\
p=.000\end{array}$ \\
\hline $\begin{array}{l}\text { The government should have stronger standards on fuel } \\
\text { efficiency of cars }\end{array}$ & $\begin{array}{l}2.69 \\
(1.23)\end{array}$ & $\begin{array}{l}3.99 \\
(0.89)\end{array}$ & $\begin{array}{l}U=1267401 \\
p=.000\end{array}$ \\
\hline $\begin{array}{l}\text { Climate change has been established as a serious problem } \\
\text { and immediate action is necessary }\end{array}$ & $\begin{array}{l}2.64 \\
(1.31)\end{array}$ & $\begin{array}{l}4.20 \\
(0.93)\end{array}$ & $\begin{array}{l}U=1102534 \\
p=.000\end{array}$ \\
\hline $\begin{array}{l}\text { Climate change is caused by human activities related to } \\
\text { using energy }\end{array}$ & $\begin{array}{l}2.79 \\
(0.98)\end{array}$ & $\begin{array}{l}4.03 \\
(0.95)\end{array}$ & $\begin{array}{l}U=1102040 \\
p=.000\end{array}$ \\
\hline $\begin{array}{l}\text { There are benefits to people in our country from climate } \\
\text { change }\end{array}$ & $\begin{array}{l}2.81 \\
(1.03)\end{array}$ & $\begin{array}{l}2.50 \\
(1.02)\end{array}$ & $\begin{array}{l}U=2472825.5, \\
p=.000\end{array}$ \\
\hline Behaving sustainably can have health benefits & $\begin{array}{l}2.68 \\
(1.35)\end{array}$ & $\begin{array}{l}4.05 \\
(0.81)\end{array}$ & $\begin{array}{l}U=1309070.5 \\
p=.000\end{array}$ \\
\hline
\end{tabular}


Some interesting differences emerged from the detailed analysis of items on the questionnaire. For example, the UK respondents exhibited a stronger commitment to changing their personal behaviour than Chinese respondents ('I would do more to save energy if I knew how'). This may be because they were more likely than the Chinese respondents to feel that their actions could make a difference (fewer agreed with the statement, 'The way I personally use energy does not make a difference to the national energy situation' and more agreed with the statement that 'Behaving sustainably can have health benefits'). However, UK respondents were also more likely to believe that 'Scientists will find ways to solve energy problems', 'The government should have stronger standards on fuel-efficiency of cars', and that 'More wind farms should be developed ... even if they are located in scenic environments', so there was a sense of shared responsibility with scientists and government.

Chinese participants were less likely to feel that their own use of energy made a difference to the national energy situation but they were more likely to perceive themselves as having agency in influencing the government and companies to do something about energy issues (I can influence what the government does [what companies do] about energy problems'). They were significantly more likely than UK respondents to agree with the statement, 'I trust the government to do something about any energy problems'. Significant differences in responses to the questions about climate change were also received from respondents from the two countries. UK respondents were more likely to perceive climate change as a serious problem, and one caused by human activities and Chinese respondents were more likely to agree with the statement 'There are benefits to people in our country from climate change'. These were some of the largest absolute differences in response of this set of questions, with near-universal agreement amongst UK respondents about the scale and nature of the challenge, compared to a near neutral response from the Chinese participants.

\subsection{Behaviours}


There were significant differences in self-reported behaviours between the Chinese and UK respondents (see Table 4). The UK students were significantly more likely to report engaging in a wide range of energysaving behaviours, from the personal (e.g. turning off lights; using cars less), to the financial (buying things that involve less energy; using rechargeable batteries), and the social (trying to convince others to act responsibly). The exceptions to this pattern were two items where the Chinese respondents were more likely to undertake a specific behaviour (avoiding charging mobile phones at night and participating in environmental campaigns), and three other items in which no significant differences were found between the two groups (paying more for environmentally friendly products; trying to learn what they can do to help solve environmental issues; and talking with others about environmental issues). There was also a notable difference in the range of responses offered by UK participants (with turning off lights being almost universal and participating in environmental campaigns unusual), whereas the Chinese sample reported little difference in their likelihood of undertaking different activities. 
Table 4: Self-reported behaviours (Highlighted box shows which group had higher likelihood of undertaking each behaviour where significant). [1 = never, $4=$ always] [** significant at $0.001,--$ not significant]

\begin{tabular}{|c|c|c|c|}
\hline Behaviour: & China \% & UK \% & Significance \\
\hline Turn off lights when they are not in use & 2.21 & 3.61 & $* *$ \\
\hline Turn down the heat & 2.26 & 3.08 & $* *$ \\
\hline Try to save water & 2.24 & 3.03 & $* *$ \\
\hline Walk or cycle short distances instead of going by car & 2.22 & 3.40 & $* *$ \\
\hline $\begin{array}{l}\text { Buy things that are likely to involve less energy or resource } \\
\text { use }\end{array}$ & 2.27 & 2.45 & $* *$ \\
\hline Pay a bit more for environmentally friendly products & 2.41 & 2.43 & -- \\
\hline Avoid charging mobile phones overnight & 2.45 & 2.01 & $* *$ \\
\hline $\begin{array}{l}\text { Turn off standby button on the TV or switch appliances off at } \\
\text { the plug }\end{array}$ & 2.36 & 2.95 & $* *$ \\
\hline Use rechargeable batteries & 2.42 & 2.55 & $* *$ \\
\hline Try to learn what I can do to help solve environmental issues & 2.45 & 2.50 & -- \\
\hline Talk with others about environmental issues & 2.47 & 2.47 & -- \\
\hline $\begin{array}{l}\text { Try to convince friends to act responsibly towards the } \\
\text { environment }\end{array}$ & 2.42 & 2.51 & $* *$ \\
\hline
\end{tabular}



petitions)

\section{Discussion:}

The findings above illustrate the responses of students in the UK and China to an energy literacy survey in the domains of knowledge, attitudes and behaviour. In this discussion, we pull out key differences between the respondents in the two countries and offer some possible explanations for these differences, as well as considering the implications of our findings for theory and practice regarding behaviour change.

\subsection{Cognitive Dimension}

In terms of the cognitive element of energy literacy, although the UK participants had higher selfreported knowledge, this was not matched by their actual knowledge when tested, and the Chinese group scored significantly higher on knowledge about energy. The unreliability of self-reports of knowledge has been identified by previous research in which performance on tests did not match perceptions about what people knew, with the tendency to over-estimate being commonplace (Murphy and Olson, 2008). Gender differences in perceived knowledge (with males scoring higher on academic self-concept) have been evidenced by Cooper et al. (2018), amongst others, but these would be more likely to have led to higher reported knowledge scores in the Chinese group in which there were proportionally more males. There is also some evidence of cultural differences in academic self-concept, with Yeung and Han (2017) demonstrating that Anglo-background students in Australian schools had higher self-concept in English than Chinese-background students, despite lower actual performance. Although the majority of both groups considered themselves novices when it came to knowledge about energy, Chinese participants provided more correct responses to almost all questions testing knowledge; the only exception being a practical question about which behaviours saved most energy. This might be indicative of a better educational system, or a more competitive culture in the Chinese context, though it 
may also be related to differences in disciplinary mix between the two sets of students (see Cotton et al., 2015) - there were notably more Science and Technology students in the Chinese groups, and more Medical and Nursing students in the UK group.

Notably, although the Chinese participants gave more correct answers to the knowledge questions about energy saving, they were less likely to identify climate change as anthropogenic, which indicates some serious gaps in their knowledge. This may be related to the sources of information cited by each group: The Chinese participants reported getting most of their information from the internet, whereas the UK participants were more likely cite formal educational contexts. Geall (2018) notes that despite climate change rising up the media agenda in China, journalists reported doubts about its scientific validity so it is perhaps unsurprising that survey respondents would share this view. It is arguable that the tendency for Chinese students to gain their information from internet sources is particularly problematic in a context where the internet is heavily controlled and where research suggests that even academic staff find it difficult to get accurate information about environmental issues (Cotton and Winter, 2018). Although the UK students reported gaining most of their information through formal education, it should be noted that research in the UK on members of the public has suggested that television is a major source of information (Borne, 2009).

\subsection{Affective Dimension}

Turning to the affective dimension of energy literacy, this research found that the UK participants put more importance on individual and government energy-saving actions and had a stronger belief in the importance of human-made climate change. Although this may be related to the gender difference between the samples since some research suggests that females tend to have more pro-environmental views (Zelezny, 1999; Xiao and McCright, 2015), the extent of the difference makes this unlikely as a full explanation. Intriguingly, one of the initial explanations given for this gender difference is that women have a lower level of trust in government and in science which makes them more enthusiastic in making 
personal commitments to the environment; however, more recent research suggests that this difference in institutional trust has largely dissipated, and that institutional trust may in any case have a positive relationship with environmental concern (Xiao and McCright, 2015). In the case of the Chinese respondents, they were more likely to feel that individual change would not make much impact on the national energy situation, but they expressed a stronger sense of agency and trust towards government and businesses.

As measured by the New Ecological Paradigm Scale (NEP), UK students also had a significantly more ecological world-view. However, these findings perhaps point to the difficulty of intercultural studies in drawing meaningful comparisons: air-pollution in Chinese cities is a far more immediate and visible problem than in the UK, and some of the NEP measures are framed in phrases that would be more familiar to UK students, for example, 'earth is like a spaceship'. Although the NEP has been used previously in research in China (e.g. Liu et al., 2010; Wu, 2012), it has not been unproblematic and variable levels of reliability have been observed. Wu (2012) found acceptable internal consistency of the scale, but somewhat incoherent responses, leading them to suggest that this might be "an indicator of the current state of environmental awareness among children in China" (p. 116) although it may also reflect difficulties in translating the scale effectively. To find meaningful policy interventions in response to the NEP findings would require further exploration within the specific culture.

\subsection{Conative Dimension}

Finally, the conative dimension (reported behaviours or behavioural motivations) illustrated differences in the likelihood of undertaking energy saving behaviours between the two groups. UK participants were more likely to report engaging in almost every behavioural change, except for the communal response of participating in environmental campaigns which was more popular with the Chinese respondents. This can be referenced against the wider social and cultural context, within which Chinese students trust the government to provide the necessary opportunities, technologies and infrastructures to solve energy 
problems and stronger social norms displayed in a smaller range of responses overall. UK students were significantly more likely to try to convince others to act responsibly towards the environment albeit with a greater range of responses. Neither group were keen to pay more for environmentally friendly products, which may reflect their financial position as students, or a more general limitation to people's 'willingness to pay' for sustainability. However, research by Spence et al. (2014) suggests that framing of energy saving - in terms of $\mathrm{CO}_{2}$ saved, rather than financial savings - may help prompt behavioural change, so this might be a future consideration. The concept of 'behavioural spillover' may provide something of an explanation for why the UK students appeared to report more energy conservation behaviours.

Behavioural spillover describes a tendency for individuals who have been encouraged to change a specific behaviour for environmental reasons to subsequently adopt additional pro-environmental behaviours, as a protective response to avoid cognitive dissonance (Thøgersen, 1999). There have been significant campaigns in UK schools which have targeted activities such as turning off lights and recycling which, whilst they may not lead to significant energy savings, could have such a ripple effect in other areas.

\subsection{Implications for Theory and Practice}

Climate change and energy education should arguably be part of every country's education policy - but the experience of the Chinese participants who were highly knowledgeable about energy and yet less inclined to engage in energy saving than their less well-informed UK counterparts - demonstrates that simply adding knowledge content to the curriculum is not sufficient. There may be a need for greater efforts to link formal learning with daily life to enhance awareness of how energy is used in everyday practices and illustrate how changing behaviours affect energy use (Hards, 2013). This is particularly important in the Chinese context where strong academic knowledge of energy did not appear to prompt lifestyle changes. Limitations were also found in terms of critical thinking - with the extent of climate change scepticism in China a worrying trend. Ensuring wider awareness of the risks of 'fake news' and misinformation is essential to engender effective energy saving policies. Research in the UK (Hafner et al., 2019) has also identified a number of psychological barriers to understating energy saving measures - 
and these may also impact on respondents even where they indicate a behavioural intention to change.

Barriers included action inertia (habits are difficult to change) and lack of awareness of the issue or how to resolve it (Hafner et al., 2019), thus the embedding of very practical advice on how to change behaviour and why may increase engagement of individuals in both contexts.

At a wider level, cross-cultural theories may offer a way of understanding the differences observed between respondents in China and the UK. Notwithstanding the critique raised in the introduction, there is some evidence that distinctive cultural worldviews exist in different countries that shape both policy and individual or social practices (e.g. Hofstede, 2001; Douglas, 1970). Taking Hofstede's scores for China and the UK, they indicate a substantial difference in the 'Power-Distance' index between the two countries with China having a much higher score (Hofstede Insights, nd). This would indicate (in general) a higher likelihood of trusting in others, and a higher likelihood of harmony between powerful and powerless. Both of these characteristics may help explain the higher level of trust in business and government exhibited by the Chinese respondents. China and the UK also differ on the 'individualism' index, with the UK exhibiting a much stronger individualistic culture, and China strong on collectivism. Again, this fits with the findings that Chinese respondents were less likely to undertake individual behavioural changes, but more likely to participate in environmental campaigns. Similarly, Douglas (1970) - and other scholars subsequently - argues that different models of social organisation can be placed along two axes using the 'Grid-Group' Framework. One axis represents the 'group' tendencies of a society (the relative importance of the group as compared to the individual), and the other the 'grid' dimension, representing the importance of rules and hierarchy. Dang (2018) describes China as having a "distinctive top-down and hierarchical culture that is embedded not only in policy design, but also in intergovernmental relations" (p.18). Dang also notes the culture of collectivism in China which is in contrast to the UK's individualistic society and may explain the increased emphasis placed by Chinese respondents on social as opposed to individual actions. 
It is important to note that further work is needed to explore the different ways in which energy saving is both understood and enacted in China and the UK. Detailed qualitative research would offer opportunities for exploring the issues around trust and agency in specific contexts that are hinted at here. We also acknowledge that our sample relied on university students whose perspectives may not be the same as the wider population in these countries. By drawing out general explanations, we do not intend to imply a homogeneity of responses even from within our sample, far less to expect them to represent an entire country's population. However, the similarity of the respondents in each location does give the findings comparability which would be difficult to achieve in a more diverse sample.

The framework of energy literacy provides a way of gaining insight into the knowledge, attitudes and behaviours of the participants in this study, and so suggests possible policy directions and interventions. The fact that differences in energy literacy were found which appear to align with the cultural context provides support for the social change theories discussed earlier. From the point of view of policy, it is important to consider energy saving as a culturally-mediated behaviour, meaning the focus of energy policies should vary in different countries and cultural contexts. The cultural differences in levels of external trust and individual and collective agency offer support for consideration of market segmentation (Barr, 2008) in policy-making rather than adopting a 'one size fits all' approach. When promoting activities to save energy, these should include a mixture of individual and communal actions as these may appeal to different audience sectors. For example, in the Chinese context, social norms and expectations may have a stronger impact on energy-related behaviour than they would in the UK (see Yue et al., 2020 for an example of this approach in action). As Langbroek et al. (2016) report, policy incentives may be more efficient if targeted at early adopters and specific niche markets. It can be contended that HE students, as 'future leaders' are an effective 'market' to focus energy-literacy efforts. Embedding behaviour change campaigns (such as turning off lights) into educational or organisational contexts may also be useful given the spillover effects of undertaking small scale behavioural changes. 
If the transition model is accepted then policy directions must incorporate a substantial re-structuring of energy infrastructure into low-carbon models, utilising a long-term policy perspective. As Hargreaves (2011) notes, "Bringing about pro-environmental patterns of consumption, therefore, does not depend upon educating or persuading individuals to make different decisions, but instead on transforming practices to make them more sustainable" (p. 83). If we accept the need for non-linear behaviour change models, the policy implications become extremely complex, since they involve the interaction of numerous actors at multiple levels. In considering the social practice model, it is clear that policy should focus on domains of practice (such as institutions or organisations) rather than simply on individuals. Instead of (or in addition to) providing additional information to remedy an individual knowledge deficit, key contextual variables in this case might include consideration of collective responsibilities, particularly where these are culturally salient, and making changes to organisations and society that make sustainable behaviour more likely.

\section{Conclusions}

This research provides novel insights into differences in energy literacy between respondents in the UK and China. While energy literacy across these respondents was relatively high, there were significant differences between participants in the two contexts across the different elements (knowledge, attitudes and behavioural intentions). Differences included the origins and levels of knowledge, attitudes towards energy saving and wider sustainability issues, and behavioural intentions. The findings suggest a potential exists for UK students to benefit from increased attention in curricula to scientific or technical knowledge, and for Chinese students to have more information made available from reliable sources on the impacts of their individual and group energy behaviours. Whilst the correlations and causative forces between the subcomponents of energy literacy, of cognition, attitudes and behaviours can continue to be explored, this research indicates a need to consider influences beyond the level of the individual. For a cleaner, more sustainable future, policy-makers should be looking to a combination of education and structural change, tailored to the cultural context. 


\section{References:}

Ajzen, I. 1991. The theory of planned behavior. Organizational Behavior and Human Decision Processes. 50 (2), 179-211.

Al-Obaidi, A.S.M. and NguyenHuynh, T. 2018. Renewable vs. conventional energy: which wins the race to sustainable development? IOP Conference Series: Materials Science and Engineering. 434. Available online at: https://iopscience.iop.org/article/10.1088/1757-899X/434/1/012310 (accessed 29/07/20)

Bodzin, A.M., Fu, Q., Peffer, T. \& Kulo, V. 2013. Developing Energy Literacy in US Middle-Level Students Using the Geospatial Curriculum Approach, International Journal of Science Education. 35:9, 1561-1589.

Attari, S.Z., DeKay, M.L., Davidson, C.I. and Bruine de Bruin, W. 2010. Public Perceptions of Energy Consumption and Savings. Proceedings of the National Academy of Sciences. 107 (37), 6.

Borne, G. 2009. Achieving sustainable lifestyles or encouraging a counter-reflexivity: exploring motivations for sustainability in a mediated risk society. Local Environment. 14 (1), 95-109.

Brewer, R.S., Xu, Y., Lee, G.E., Katchuck, M., Moore, C.A. and Johnson, P.M. 2013. Three Principles for the Design of Energy Feedback Visualizations. International Journal on Advances in Intelligent Systems. 6 (3 \& 4), 188-198.

DeWaters, J. and Powers, S. 2011. Energy Literacy of Secondary Students in New York State(USA): A measure of knowledge, affect, and behavior.' Energy Policy. 39(3), 1699-710.

Bang, H., Ellinger, A.E., Hadjimarcou, J. and Traichal, P.A. 2000. Consumer concern, knowledge, belief, and attitude toward renewable energy: An application of the reasoned action theory. Psychology \& Marketing. 17(6), 449-468.

Barkema, H.G., Chen, X., George, G., Luo, Y. and Tsui, A.S. 2015. West meets East: New concepts and theories. Academy of Management Journal. 58(2), 460.

Barr, S. 2008. Environment and Society: Sustainability, Policy and the Citizen. Ashgate, Aldershot. 
Barr, S. and Gilg, A.W. 2007. A Conceptual Framework for Understanding and Analyzing Attitudes Towards Environmental Behaviour. Geografiska Annaler: Series B, Human Geography. 89(4), 36179.

Barrow, L. and Morrisey, J.T. 1989. Energy Literacy of Ninth-Grade Students: A Comparison between Maine and New Brunswick. The Journal of Environmental Education. 20(2), 4.

Blake, J. 1999. Overcoming the 'Value-Action Gap' in Environmental Policy: Tensions between National Policy and Local Experience. Local environment. 4(3), 257-78.

Chaplain, C. 2019. Manifesto environment plans: here's how each party has pledged to tackle climate change in their general election policies. I-News. $28^{\text {th }}$ November 2019.

Cooper, K.M., Krieg, A. and Brownell, S.E. 2018. Who perceives they are smarter? Exploring the influence of student characteristics on student academic self-concept in physiology. Advances in Physiology Education. 42(2), 200-208.

Cotton, D., Bailey, I., Warren, M. and Bissell, S. 2009. Revolutions and Second-Best Solutions: Education for Sustainable Development in Higher Education. Studies in Higher Education. 34(7), 15.

Cotton, D., Miller, W., Winter, J., Bailey, I. and Sterling, S. 2015 Developing students' energy literacy in higher education. International Journal of Sustainability in Higher Education. 16 (4), 456-473.

Cotton, D.R.E, Shiel, C. and do Paco, A. 2016a. Energy saving on campus: A comparison of students' attitudes and behaviours in the UK and Portugal. Journal of Cleaner Production. 129, 586-595.

Cotton, D.R.E, Miller, W., Winter, J. Bailey, I. \& Sterling, S. 2016b. Knowledge, agency and collective action as barriers to energy-saving behaviour. Local Environment. 21(7), 883-897.

Cotton, D.R.E. and Winter, J. 2018. Hearing Different Voices: Teaching about Sustainability in Chinese Higher Education. International Consortium for Educational Development Conference. Vancouver, Canada. Available online at: https://www.academia.edu/43888661/Hearing Different Voices Teaching about Sustainability in Chinese Higher Education (accessed 18 Aug 2020). 
Dang, W. 2018. How culture shapes environmental public participation: case studies of China, the Netherlands, and Italy, Journal of Chinese Governance. DOI: 10.1080/23812346.2018.1443758

DEFRA (Department for Environment, Food and Rural Affairs). 2008. A Framework for Pro-Environmental Behaviours. DEFRA, London.

Douglas, M. 1970. Natural Symbols: explorations in cosmology. Pantheon Books, New York.

Dunlap, R. E. 2008. The New Environmental Paradigm Scale: From Marginality to Worldwide Use. The Journal of Environmental Education, 40(1), 3-18.

Fishbein, M., \& Ajzen, I. 1975. Belief, Attitude, Intention, and Behavior: An Introduction to Theory and Research. Addison-Wesley, Reading, MA.

Fougère, M., \& Moulettes, A. 2007. The Construction of the Modern West and the Backward Rest:

Studying the Discourse of Hofstede's Culture's Consequences. Journal of Multicultural Discourses. 2(1), 1-19.

Franco, D., Cotton, D., do Paço, A. and Schepers, M. 2018. Energy Efficiency projects in a living lab Higher Education Institution: a connection between sustainability and wellbeing. Poster presentation at 24th International Sustainable Development Research Society Conference. University of Messina and University of Pescara, Italy. 13th-15th June, 2018

Gao, H., Winterich, K.P. and Zhang, Y. 2016. All That Glitters Is Not Gold: How Others' Status Influences the Effect of Power Distance Belief on Status Consumption. Journal of Consumer Research. 43(2), 265-281.

Gardner, G.T. and Stern, P.C. 2008. The Short List: The Most Effective Actions U.S. Households Can Take to Curb Climate Change. Environment: Science and Policy for Sustainable Development. Available online at: https://www.teachgreenpsych.com/wp-content/uploads/2018/01/Gardner-Stern2008-The-short-list-The-most-effective-actions-U.S.-households-can-take-to-curb-climatechange.pdf (accessed 28/02/20)

Geall, S. 2018. Climate-Change Journalism and "Edgeball" Politics in Contemporary China. Society \& Natural Resources. 31(5), 541-55. 
Geller, H., Harrington, P., Rosenfeld, A.H., Tanishima, S. and Unander, F. 2006. Polices for increasing energy efficiency: Thirty years of experience in OECD countries. Energy Policy. 34(5), 556-573.

Genc, M., and Akilli, M. 2016. Modelling the relationships between subdimensions of environmental literacy. Applied Environmental Education \& Communication. 15(1), 58-74.

Hafner, R.J., Pahl, S., Jones, R.V. and Fuertes, A. 2019. Energy use in social housing residents in the UK and recommendations for developing energy behaviour change interventions. Journal of Cleaner Production. 251, 119643.

Hards, S. K. 2013. Status, stigma and energy practices in the home. Local Environment, 18(4), 438-454.

Hargreaves, T. 2011. Practice-ing behaviour change: Applying social practice theory to pro-environmental behaviour change. Journal of Consumer Culture. 11(1), 79-99.

HEFCE (Higher Education Funding Council for England). 2008. HEFCE strategic review of sustainable development in higher education in England. Available online at: http://www.psi.org.uk/pdf/2008/HEFCE FINAL PUBLISHED Jan08.pdf (accessed 17/03/20).

Hofstede, G. 2001. Culture's consequences: Comparing values, behaviors, institutions and organizations across nations (2nd ed.) Sage, Thousand Oaks, CA.

Hofstede Insights (no date). Online resource available at: https://www.hofstede-insights.com/countrycomparison/china,the-uk/ (accessed 28/02/20)

Hopkinson, P., Hughes, P., \& Layer, G. 2008. Sustainable graduates: linking formal, informal and campus curricula to embed education for sustainable development in the student learning experience. Environmental Education Research. 14(4), 435-454.

IEA. 2019. World Energy Outlook 2019. International Energy Agency. Available online at: https://www.iea.org/reports/world-energy-outlook-2019 (accessed 28/02/20).

IEA. 2020. Global $\mathrm{CO}_{2}$ emissions in 2019. International Energy Agency. Available online at: https://www.iea.org/articles/global-co2-emissions-in-2019 (accessed 28/02/20).

Jackson, T., 2005. Motivating Sustainable Consumption: A review of evidence on consumer behaviour and behavioural change. A report to the Sustainable Development Research Network, as part of the 
ESRC Sustainable Technologies Programme. Available online at:

http://sustainablelifestyles.ac.uk/sites/default/files/motivating sc final.pdf (accessed 28/02/20).

Kim, M.-S. 2007. Our Culture, Their Culture and Beyond: Further Thoughts on Ethnocentrism in Hofstede's Discourse. Journal of Multicultural Discourses. 2(1), 26-31.

Kollmuss, A., \& Agyeman, J. 2002. Mind the Gap: Why do people act environmentally and what are the barriers to pro-environmental behavior? Environmental Education Research. 8(3), 239-260.

Lane, B. \& Potter, S. 2007. The adoption of cleaner vehicles in the UK: exploring the consumer attitudeaction gap. Journal of Cleaner Production. 15(11), 1085-1092.

Langbroek, J., Franklin, J.P and Susilo, Y.O. 2016. The effect of policy incentives on electric vehicle adoption. Energy Policy. 94, 94-103.

Leal Filho, W. (Ed.) 2010. Universities and Climate Change: Introducing Climate Change to University Programmes. Springer-Verlag, Berlin.

Lee, L.-S., Lee, Y.-F., Altschuld, J. W., \& Pan, Y.-J. 2015. Energy literacy: Evaluating knowledge, affect, and behavior of students in Taiwan. Energy Policy. 76, 98-106.

Li, L. and Taeihagh, A. 2020. An in-depth analysis of the evolution of the policy mix for the sustainable energy transition in China from 1981 to 2020. Applied Energy. 263.

Liu, J., Ouyang, Z., \& Miao, H. 2010. Environmental attitudes of stakeholders and their perceptions regarding protected area-community conflicts: A case study in China. Journal of Environmental Management. 91, 2254-2262.

Lorenzoni, I., Nicholson-Cole, S. and Whitmarsh, L. 2007. Barriers Perceived to Engaging with Climate Change among the UK Public and Their Policy Implications. Global Environmental Change. 17(3), 445-59.

Murphy, T. P., \& Olson, A. M. 2008. The third Minnesota report card on environmental literacy: A survey of adult environmental knowledge, attitudes and behavior. Available online at: https://www.leg.state.mn.us/docs/2009/other/090329.pdf (Accessed 17/03/20).

O’Riordan, T. 1981. Environmentalism. Pion-Methuen, London. 
QAA (Quality Assurance Agency). 2014. Education for Sustainable Development: Guidance for UK higher education providers. Available online at: https://www.qaa.ac.uk/docs/qaa/qualitycode/education-sustainable-development-guidance-june-14.pdf?sfvrsn=1c46f981 8 (Accessed $17 / 03 / 20)$

Reckwitz A. 2002. Toward a theory of social practices: a development in culturalist theorizing. European Journal of Social Theory. 5, 243-263

Ripple, W.J., Wolf, C., Newsome, T.M., Galetti, M., Alamgir, M., Crist, E., Mahmoud, M.I. and Laurance, W.F. 2017. World Scientists' Warning to Humanity: A Second Notice, 15,364 scientist signatories from 184 countries. BioScience, 67 (12): 1026-1028

Rokeach, M. 1973. The nature of human values. Free Press.

Rotmans, J., Kemp, R., van Asselt, M. 2001. More evolution than revolution: transition management in public policy. Foresight. 3, 15-31.

Sarkis, A.M. 2017. A comparative study of theoretical behaviour change models predicting empirical evidence for residential energy conservation behaviours. Journal of Cleaner Production. 141, 526537.

Schwartz, S. H. 2012. An Overview of the Schwartz Theory of Basic Values. Online Readings in Psychology and Culture, 2(1). Available online at: http://dx.doi.org/10.9707/2307-0919.1116 (Accessed $17 / 03 / 20)$

SCR. 2006. I will if you will: Towards sustainable consumption. Final report from Sustainable Consumption Roundtable, September 2004-March 2006, London.

Senbel, M., Ngo, V.D. and Blair, E. 2014. Social mobilization of climate change: University students conserving energy through multiple pathways for peer engagement. Journal of Environmental Psychology. 38, 84-93.

Shi, D., Wang, L. and Wang, Z. 2019. What affects individual energy conservation behavior: Personal habits, external conditions or values? An empirical study based on a survey of college students. Energy Policy. 128, 150-161. 


\section{Journal Pre-proof}

Shove, E. 2010. Beyond the ABC: Climate change policy and theories of social change. Environment and Planning A. 42, 1273-85.

Spence, A., Leygue, C., Bedwell, B., O'Malley, C. 2014. Engaging with energy reduction: Does a climate change frame have the potential for achieving broader sustainable behaviour? Journal of Environmental Psychology. 38, 17-28.

Stephenson, J., Barton, B., Carrington, G., Gnoth, D., Lawson, R. and Thorsnes, P. 2010. Energy cultures: A framework for understanding energy behaviours. Energy policy. 38(10), 6120-6129.

Stephenson, J., Barton, B., Carrington, G., Doering, A., Ford, R., Hopkins, D. and Lawson, R. 2015. The energy cultures framework: Exploring the role of norms, practices and material culture in shaping energy behaviour in New Zealand. Energy Research \& Social Science. 7, 117-123.

Sterling, S., Maxey, L., \& Luna, H. (Eds.). 2013. The Sustainable University: Progress and prospects. Routledge, London.

Stern, P. 2000. Toward a coherent theory of environmentally significant behavior. Journal of Social Issues. $56,407-24$.

Sütterlin, B., Brunner, T. A., \& Siegrist, M. 2011. Who puts the most energy into energy conservation? A segmentation of energy consumers based on energy-related behavioral characteristics. Energy Policy. 39(12), 8137-8152.

Thøgersen, J. 1999. Spillover processes in the development of a sustainable consumption pattern. Journal of Economic Psychology. 20, 53-81.

Tsui, A.S., Ou, A.Y. and Nifadkar, S. 2007. Cross-National Cross-Cultural Organizational Behavior Research: Advances, Gaps, and Recommendations. Journal of Management. 33(3), 426-478.

Verbong, G. and Loorbach, D. (eds). 2012. Governing the Energy Transition: reality, illusion, or necessity? Routledge, New York.

Wang, G. and Che, Y. 2007. Integration of environment education and TEFL: A perspective of global education. Journal of Kunming University of Science and Technology. 7(1), 61-65. 
Wang, Q., Xue, M., Lin, B., Lei, Z. and Zhang, Z. 2020. Well-to-wheel analysis of energy consumption, greenhouse gas and air pollutants emissions of hydrogen fuel cell vehicle in China. Journal of Cleaner Production.

Wang, Z., Sun, Y. and Wang, B. 2020. Policy cognition is more effective than step tariff in promoting electricity saving behaviour of residents. Energy Policy.

Wu, L. 2012. Exploring the New Ecological Paradigm Scale for Gauging Children's Environmental Attitudes in China. The Journal of Environmental Education. 43(2), 107-120.

Xiao, C. and McCright, A.M. 2015. Gender Differences in Environmental Concern: Revisiting the Institutional Trust Hypothesis in the USA. Environment and Behaviour. 1, 17 -37.

Yeung A. and Han F. 2017. Chinese-background Australian students' academic self-concept, motivational goals, and achievements in math and English, in Li G., Ma W. (Eds.), Educating Chinese-heritage students in the global-local nexus: Achievement, challenges, and opportunities. Routledge, New York, pp. 141-159.

Yuan, X., Zuo, J. \& Huisingh, D. 2013. Green Universities in China - what matters? Journal of Cleaner Production. 61, 36-45.

Yue, T., Long, R., Chen, H., Liu, J., Liu, H. and Gu, Y. 2020. Energy-saving behavior of urban residents in China: A multi-agent simulation. Journal of Cleaner Production. 252.

Zelezny, L. C. 1999. Educational Interventions That Improve Environmental Behaviors: A Meta-Analysis. The Journal of Environmental Education. 31(1), 5-14.

Zhang, Z. 2010. Is it fair to treat China as a Christmas tree to hang everybody's complaints? Putting its own energy saving into perspective. Energy Economics. 32 (Supplement), 47-56.

Zhang, Y., Wang, Z. and Zhou, G. 2013. Antecedents of employee electricity saving behavior in organizations: An empirical study based on norm activation model. Energy Policy. 62, 1120-1127. 


\section{HIGHLIGHTS}

\section{Reducing energy demand in China and the United Kingdom:}

\section{The importance of energy literacy}

- Significant differences in energy literacy arose in 1806 students in UK and China

- Chinese respondents demonstrated more knowledge about energy than UK respondents

- UK respondents demonstrated more positive attitudes and energy saving behaviours

- Cultural context, including trust in government impacts on energy-saving behaviours

- Combining educational and structural change will aid transition to a cleaner world 


\section{Declaration of interests}

$\bigotimes$ The authors declare that they have no known competing financial interests or personal relationships that could have appeared to influence the work reported in this paper.

$\square$ The authors declare the following financial interests/personal relationships which may be considered as potential competing interests: 